\title{
O Movimento Plus Size e o Corpo
}

Bárbara Pavei Souza

Doutoranda e Mestre pelo Programa de Pós-Graduação em Ciências da Linguagem pela Universidade do Sul de Santa Catarina - UNISUL. / barbarapaveis@gmail.com

Orcid: 0000-0003-4438-5363/ lattes

Enviado $31 / 10 / 2018$ /Aceito 20/12/2018 


\title{
O Movimento Plus Size e o Corpo
}

\begin{abstract}
RESUMO
Os efeitos de sentido do corpo belo são social e historicamente progressivos, balizados por estereótipos culturais, sociais, de classes, políticos ou religiosos. A mídia e a moda também possuem forte influência nos padrões de beleza impostos. A mídia surge como um lugar privilegiado de constituição, formulação e circulação dos sentidos do que pode ser um corpo belo ou não, enquanto legitimadora de instituições que determinam o que pode e o que não pode ser dito/mostrado em diferentes espaços. A moda, por sua vez, é um espaço de mercado. Sendo assim, o movimento plus size surge como uma necessidade de aceitação e interação dos corpos gordos na moda. No entanto, a condição do corpo gordo não muda, mudam-se as nomeações para produzir um efeito de que esse corpo é possível, mas ele continua sendo impossível dentro dos aspectos de padronização das instituições.
\end{abstract}

Palavras-chave: moda; mídia; corpo. 


\title{
The Movement Plus Size and the Body
}

\begin{abstract}
The beautiful body sense effects are socially and historically progressive, marked by cultural, social, class, political or religious stereotypes. The media and fashion also have a strong influence on the beauty standards imposed. The media appears as a privileged place of constitution, formulation and circulation of the senses of what can be a beautiful body or not, legitimating institutions that determine what can and can't be said/shown in different spaces. Fashion, in turn, is a market space. Thus, the plus size movement emerges as a need for acceptance and interaction of fat bodies in fashion. However, the condition of the fat body does not change, appointments are changed to produce an effect of which this body is possible, but it remains impossible within the standardization aspects of institutions.
\end{abstract}

Keywords: fashion; media; body. 


\title{
El Movimiento Plus Size y el Cuerpo
}

\begin{abstract}
RESUMEN
Los efectos del significado del cuerpo hermoso son progresivos social e históricamente, marcados por estereotipos culturales, sociales, de clase, políticos 0 religiosos. Los medios de comunicación y la moda también tienen una fuerte influencia en los estándares de belleza impuestos. Los medios emergen como un lugar privilegiado de constitución, formulación y circulación de los sentidos de lo que puede ser un cuerpo hermoso o no, como un legitimador de instituciones que determinan lo que puede $y$ no puede decirse/mostrarse en diferentes espacios. La moda, a su vez, es un espacio de mercado. Por lo tanto, el movimiento plus size surge como una necesidad para la aceptación e interacción de los cuerpos gordos en la moda. Sin embargo, la condición del cuerpo gordo no cambia, las citas se cambian para producir un efecto que este cuerpo es posible, pero sigue siendo imposible dentro de los aspectos de estandarización de las instituciones.
\end{abstract}

Palabras clave: moda; medios; cuerpo. 


\section{INTRODUÇÃO}

Enquanto matriz e suporte de significados, o corpo é complexo se pensado de diversas maneiras através do tempo e da história. A concepção do que seja um corpo esteticamente belo é sempre uma construção cultural, que varia de acordo com as sociedades existentes, variando, portanto, conforme as condições de produção de cada sociedade. Parafraseando Sant'Anna (2005), o corpo é memória mutante das leis e dos códigos de cada cultura, registro das soluções e dos limites científicos e tecnológicos de cada época, por isso, não cessa de ser (re)fabricado ao longo do tempo. Assim, é possível afirmar que o corpo é resultante de transformações ao longo dos anos, ele é permeável às marcas da cultura, passível de mudanças e é um lugar prático e direto de controle social.

[...] a história do corpo feminino é também a história de uma dominação na qual os simples critérios da estética já são reveladores: a exigência tradicional por uma beleza sempre "pudica", virginal e vigiada, impôsse por muito tempo, antes que se afirmassem libertações decisivas repercutidas nas formas e nos perfis, movimentos mais aceitos, sorrisos mais expansivos, corpos mais desnudos. A história do corpo, em outras palavras, não poderia escapar à história dos modelos de gênero e das identidades (CORBIN, COURTINE, VIGARELLO, 2012, p. 13).

Os discursos de estética surgiram no século XIX como efeito da industrialização e da urbanização. Como lembra Courtine (2005), esses movimentos transformam os hábitos das pessoas e, consequentemente, seus corpos. Nas sociedades influenciadas pela industrialização o estilo de vida ficou cada vez menos saudável, fruto do próprio produto estabelecido pela indústria, aliando-se às condições compactas da vida urbana em algumas cidades. Com o processo de industrialização e revolução tecnológica, o corpo se torna um dos principais textos do capitalismo ocidental, 
devendo modificar-se e ajustar-se constantemente às necessidades de produção, que configura suas formas a partir dos processos biotecnológicos.

O capitalismo, desenvolveu-se em fins do século XVIII e início do século XIX, socializou um primeiro objeto que foi o corpo enquanto força de produção, força de trabalho. O controle da sociedade sobre os indivíduos não se opera simplesmente pela consciência ou pela ideologia, mas começa no corpo, com o corpo. Foi no biológico, no somático, no corporal que, antes de tudo, investiu a sociedade capitalista. O corpo é uma realidade bio-política (FOUCAULT, 1989, p.80).

Foi através da "produção" de corpos sedentários resultantes das inúmeras transformações proporcionadas pelo capitalismo que o excesso de peso começou a ficar cada vez mais comum e a crescer exacerbadamente. Corpos cada vez maiores e mais pesados começaram a surgir.

[...] uma das grandes preocupações a nível mundial é a mudança nos hábitos de vida das pessoas, resultante de um processo histórico de evolução da humanidade. Desde que o homem inicia a exploração e transformação da natureza, e com o passar do tempo, vão-se criando e desenvolvendo meios para facilitar as atividades da sua rotina diária, tendo como marco histórico a Revolução Industrial. Desde logo a própria máquina começa a substituir as diversas ações motoras que o homem necessitava para executar as suas tarefas, desta forma contribuindo para a diminuição do esforço físico e do movimento corporal do ser humano (CHALITA, 2013, p. 3).

Mota (1992) analisa esta mudança na sociedade contemporânea afirmando que as alterações se desencadearam pelo rápido desenvolvimento tecnológico e científico. Essas mudanças foram tão significantes que alteraram de forma intensa o modo de vida humano, modificando assim os valores, atitudes e comportamentos, e, principalmente, os corpos pertencentes a essa sociedade.

É através da submissão dos corpos ao capitalismo, que os torna cada vez mais sedentários e consequentemente gordos, pela insatisfação sociocultural feminina e pelo poder 
aquisitivo das consumidoras de tamanhos grandes, que surgiu o movimento intitulado plus size. Dificilmente relata-se com precisão quando ocorreu a primeira aparição deste manifesto no mundo, mas acredita-se que foi nos estados americanos, em meados do século XX.

Para compreendermos a moda plus size, é relevante frisarmos que as medidas de vestuário estabelecidas para o corpo feminino sempre variaram; no entanto, sabemos que as grifes sempre seguiram o padrão caracterizado como $P, M, G$, que se refere às numerações entre 36, 38 e 40 . [...] sabemos que a moda plus size teve origem nos Estados Unidos e, segundo informações de Blogs especializados nesse assunto, 0 termo ( $p /$ lus $=$ maior e Size $=$ tamanho) surgiu no interior das indústrias de moda para classificar manequins acima da numeração 44, em meados da década de 70, mas, somente na década de 90, com a divulgação em revistas internacionais, que este ficou conhecido.

$\mathrm{Na}$ década de 90, descobriu-se também que, nos Estados Unidos, houve um aumento da população em sobrepeso, em especial as mulheres. Os empresários internacionais, então, ao perceberem que os modelos e tamanhos convencionais já não atendiam a $1 / 3$ dos consumidores, passaram a investir em roupas para esse público, voltando o olhar pela primeira vez para a 'mulher plus size' (SILVA, 2015, p. 61).

Diante destes acontecimentos, viu-se nascer um novo segmento de moda, que visava, antes de mais nada, o lucro. Intitulado moda plus size, este segmento mercadológico passou a nomear e a "incluir" esses corpos que até então apareceriam silenciados/apagados pelo capitalismo.

Esse movimento surge como uma necessidade de aceitação e interação dos corpos gordos, pois a imagem refletida do corpo comunica e expressa historicamente, diferentes contextos socioculturais.

[...] a política de identidade tem a ver com o recrutamento de sujeitos por meio do processo de formação de identidade que se dá tanto pelo apelo às identidades hegemônicas quanto pela resistência dos 
'novos movimentos sociais', ao colocar em jogo identidades que não têm sido reconhecidas, que têm sido mantidas fora da história ou que tem ocupado espaços às margens da sociedade (WOODWARD, 2012, p. 37).

Podemos afirmar que a nomeação plus size não corresponde, a princípio, a uma identidade estável e préexistente (RODRIGUES, 2010), mas reivindica por meio da enunciação, não só os sujeitos como também um lugar próprio que lhes garanta a existência e seu(s) sentido(s). Orlandi (2015) explica que as relações de poder e as condições de produção estão presentes nos processos de identificação do sujeito, e as identidades resultam desses processos, onde se estabelece a eficácia do imaginário. "Tudo isso vai contribuir para a constituição das condições em que o discurso se produz e, portanto, para seu processo de significação" (ORLANDI, 2015, p. 40). Assim sendo, o sujeito, hoje nomeado como plus size, é de ordem construída, resultado de um processo que assim o constitui.

Percebe-se que os dizeres sobre o corpo e o sujeito plus size estão presentes em enunciados de diferentes materialidades, em diversos suportes, impulsionados pelos interesses capitalistas. Esses corpos começaram a aparecer na mídia através de revistas, imagens publicitárias, encartes de moda, desfiles, blogs, propagandas etc., fazendo com que os discursos sobre eles se dispersassem, circulassem e se legitimassem.

Sabemos que a história da imprensa é a própria história da sociedade capitalista. O controle dos meios de difusão de ideias e de informações que se verifica ao longo do desenvolvimento da imprensa é reflexo dessa sociedade. A influência que a difusão impressa exerce sobre o comportamento das massas e dos sujeitos é o traço que comprova esta ligação: sociedade/consumo/imprensa. 
Ao longo do século XIX, a revista ganhou espaço, virou e ditou moda. Principalmente na Europa e também nos Estados Unidos. Com o aumento dos índices de escolarização, havia uma população alfabetizada que queria ler e se instituir, mas não se interessava pela profundidade dos livros, ainda vistos como como instrumentos da elite e pouco acessíveis. Com o avanço técnico das gráficas, as revistas tornaram-se o meio ideal, reunindo vários assuntos num só lugar e trazendo belas imagens para ilustrá-los. Era uma forma de fazer circular, concentradas, diferentes informações sobre os novos tempos, a nova ciência e as possibilidades que se abriam para a população que começava a ter acesso ao saber (SCALZO, 2003, p. 20).

A revista feminina é um marco significativo da história contemporânea, que documenta tanto a evolução da imprensa na modernidade, quanto a história social da mulher. As revistas femininas são organizadas para atuar na construção do ideário e do imaginário coletivo e, portanto, é totalmente capaz de manipular, através de seus comentários, a formação dos modos de ver e de ser de suas consumidoras.

[...] em 1693, na França, surge outra novidade. Tratava-se de uma revista de pauta variada - Mercúrio das Senhoras, a primeira de todas as revistas femininas. Mais tarde, no século XIX, elas se multiplicaram. Trouxeram uma fórmula editorial voltada basicamente aos afazeres do lar e às novidades da moda- algumas ofereciam às leitoras moldes de roupas e desenhos para bordados, coisa que persiste até hoje em publicações do tipo (SCALZO, 2003, p. 22). 
A moda impulsiona o feminino na mídia e por ela é impulsionada. As primeiras grandes tiragens das revistas femininas aconteceram com a difusão dos moldes de costura, nos Estados Unidos (início do século $X X$ ). Isso pode ser considerado uma revolução, afinal, a revista ensinou as mulheres um novo modo de ser, uma nova maneira de fazer.

No início do século $X X$, as revistas para as mulheres já estavam sacramentadas como veículos significativos da cultura de massa. Com o desenvolvimento da indústria da moda, dos cosméticos, de produtos para o lar e com o progresso da publicidade, as revistas femininas se tornaram fundamentais no mercado. Portanto, podemos afirmar que a imprensa feminina está estritamente ligada ao contexto sócio-histórico que cria razões para o seu surgimento, onde os jornais e as revistas femininas funcionam como "termômetros" dos costumes de cada época, fazendo com que cada novidade seja imediatamente incorporada, desenvolvida e disseminada.

As revistas femininas existem desde que surgiram revistas no país. Elas começaram a aparecer, sem muito alarde, geralmente feitas e escritas por homens. Traziam novidades da moda, importadas da Europa, dicas e conselhos culinários, artigos de interesse geral, ilustrações, pequenas notícias e anedotas. Esse modelo foi repetido, com pequenas diferenças, durante todo o século XIX e a primeira metade do século XX. É certo que houve, também, neste período, publicações feitas de mulheres para mulheres, preocupadas com sua condição na sociedade e seus direitos, mas são poucas e a maioria teve vida curta. [...] Nos anos 1970, com a mulher entrando para valer no mercado de trabalho, há um grande crescimento no mercado de revistas femininas. Nesse momento, começam a aparecer também as revistas que não tratam as mulheres como 
simples donas-de-casa e mães, mas como profissionais em busca de realização (SCALZO, 2003, p. 33-34).

Sendo assim, sempre em busca de disseminar o novo e o que está em "alta" no mercado, no ano de 1979 lançou-se a primeira revista americana de moda e estilo para o público plus size, a "Big Beautiful Woman" (BBW Magazine).

Figura 1: Big Beautiful Woman Magazine (fevereiro de 1989, EUA).

Fonte: SOUZA, 2017, p. 79. Disponível em: https://www.riuni.unisul.br/handle/12345/3154

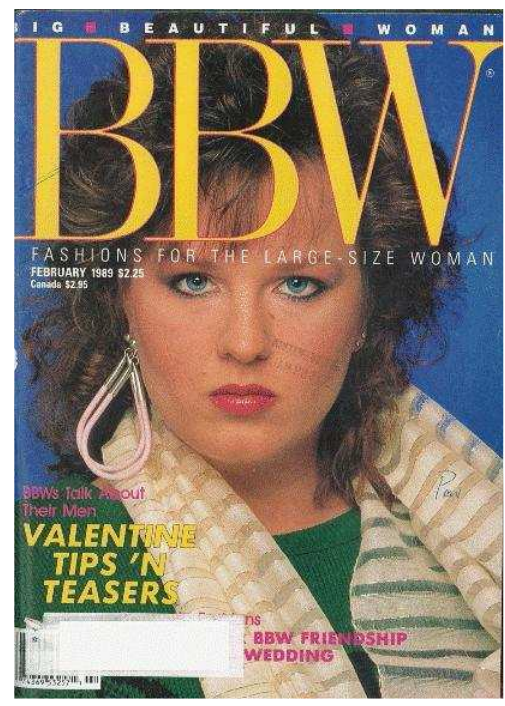

Entendo a revista como um dispositivo de constituição de uma identidade que caracteriza uma experiência da alteridade para os leitores. Por meio da relação do leitor com o outro, ele vive a experiência da contemporaneidade, inscrevendo-se num campo de saberes e códigos pré-estabelecidos que atravessam e constituem sua percepção da 'realidade' (MILANEZ, 2004, p. 185).

O corpo tem uma importância vital na atualidade, uma vez que ele serve como instrumento de comunicação para demarcar fronteiras. Dessa forma, ele sinaliza grande parte das relações que os sujeitos mantêm com os outros e consigo mesmos, tornando-se um objeto a ser incessantemente renovado, transformado. Podemos afirmar 
que o corpo em qualquer uma das formas de governo, é sempre alvo do olhar, é alvo do investimento como marca da organização política, afinal, a ordem política não só organiza os corpos em suas manifestações, como também os organiza no espaço.

Na sociedade contemporânea, a mídia pode ser entendida como um poderoso dispositivo ${ }^{1}$ de produção de identidades. Por isso, é notório um maior aparecimento dos corpos plus size em destaque nas capas de renomadas revistas internacionais, afinal, revistas assim como outras práticas discursivas também acompanham as mudanças da contemporaneidade. O controle sobre o corpo exercido pela sociedade vai ao "encontro" dos interesses do mercado (moda, mídia, publicidade), criando sentidos e necessidades para os sujeitos. Consequentemente, é notável a diferença entre o corpo que estampou a primeira revista de moda plus size, para os corpos que estampam as revistas mais atuais, afinal, compreendemos que com o poder da mídia e das imagens no cotidiano humano, a discursivização do e sobre o corpo é acentuada, isto é, o corpo que agora é espetacularizado nas mídias é aquele corpo socialmente aceito, afinal, assim como modificam-se historicamente as condições de produção social, política e econômica dos corpos, mudam-se as suas condições de estetização.

Desde os primórdios da existência humana, o corpo foi fabricado através da heterogeneidade cultural. Ou seja, sujeito e seu corpo sempre foram constituídos conforme as ideologias de cada período e de cada cultura. Os padrões estéticos consensualmente adotados pela cultura sempre dizem respeito à cosmologia vivida num dado período sóciohistórico. A atuação social sobre os sujeitos e seus corpos e a forma de vê-los e de conceituá-los é a grande marca da cultura sobre a materialidade humana. Podemos "Ier" a história de um povo e de sua época através da constituição 
dos sujeitos e pela caracterização dos corpos interseccionados pelas culturas e pelas classes sociais.

É notório como a experiência do corpo é sempre modificada pela experiência da cultura, onde o corpo aparece como a beleza concebida pelos cânones estabelecidos pela sociedade do capitalismo. Sabemos que o corpo é sempre provisório, pois ele é produzido pelo efeito que os discursos produzem sobre ele e pela ideologia dominante, que ainda é a masculina (homem, branco, classe média-alta, magro, heterossexual) que busca sempre moldar a "carne feminina".

Figura 2: Big V Magazine (2010).

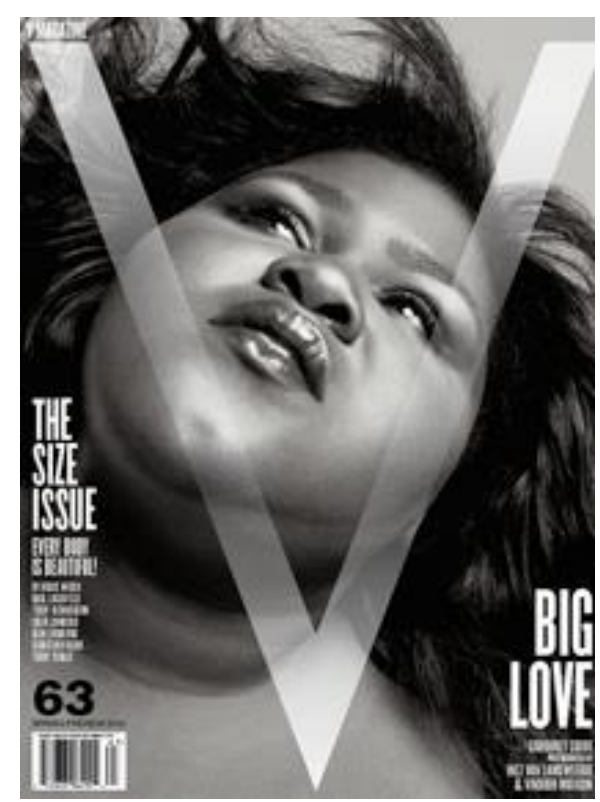

Fonte: SOUZA, 2017, p. 80. Disponível em: https://www.riuni.unisul.br/handle/12345/3154 
Figura 3: Vogue italiana (2011).

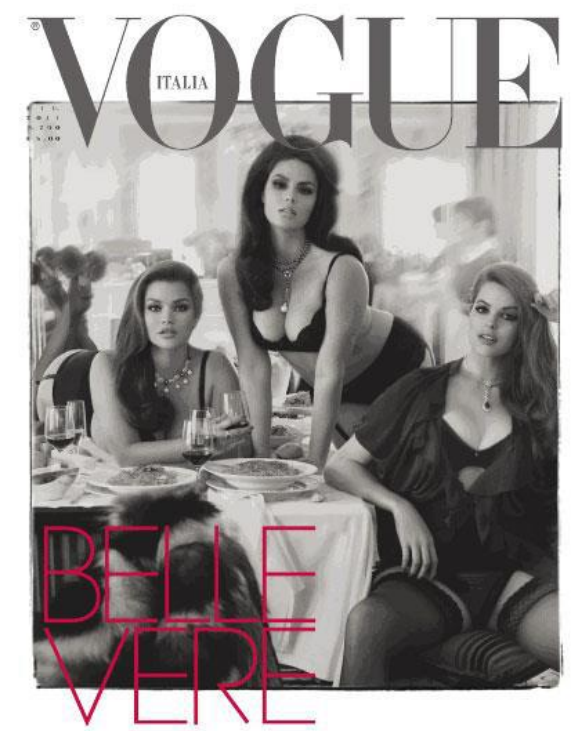

Fonte: SOUZA, 2017, p. 80. Disponível em: https://www.riuni.unisul.br/handle/12345/3154

Figura 4: Elle Francesa (2012).

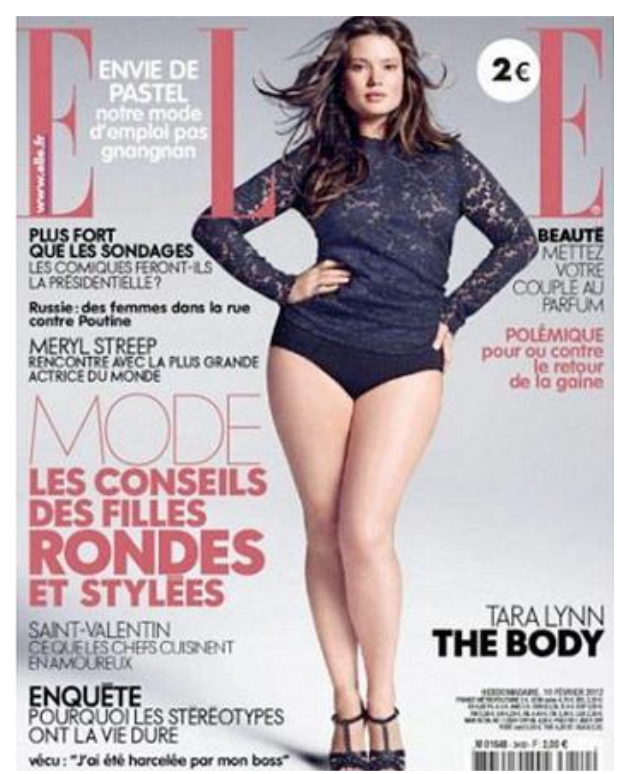

Fonte: SOUZA, 2017, p. 81. Disponível em: https://www.riuni.unisul.br/handle/12345/3154 
Figura 5: Elle Norueguesa (2015).

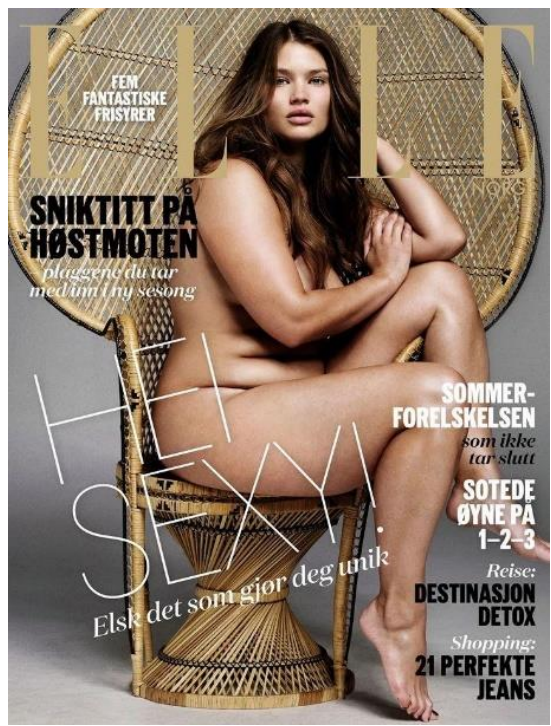

Fonte: SOUZA, 2017, p. 81. Disponível em: https://www.riuni.unisul.br/handle/12345/3154

Figura 6: Elle Brasileira (2015).

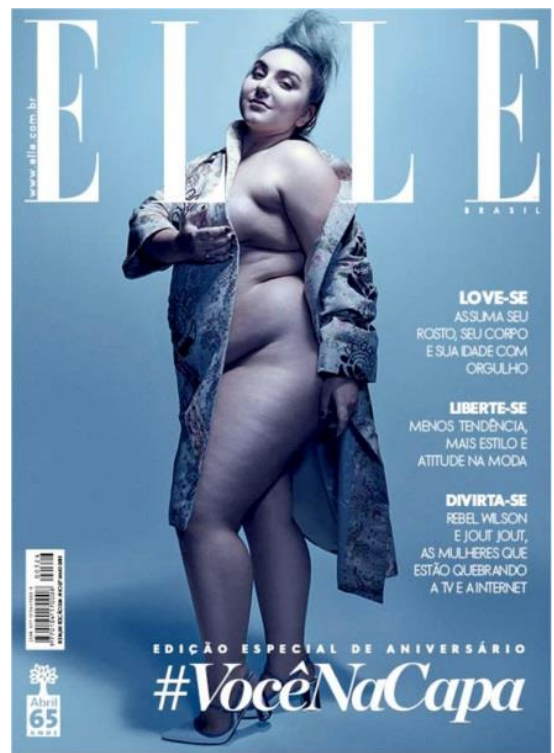

Fonte: SOUZA, 2017, p. 81. Disponível em: https://www.riuni.unisul.br/handle/12345/3154 
Figura 7: Revista Plus Model Mag (2016).

Fonte: SOUZA, 2017, p. 81. Disponível em: https://www.riuni.unisul.br/handle/12345/3154

As políticas de acessibilidade permitiram a exposição social e econômica desses corpos ditos "diferentes" - corpos que fugiam dos padrões cristalizados de beleza - e, com isso, a criação publicitária os ocupou, vendo nestes uma enorme chance de ampliação de mercado. Como já mostramos, desde a década de 80 a moda plus size tem ganhado proporção no mundo, e os discursos sobre estes corpos perpetuaram cada vez mais na grande mídia.

$\mathrm{Na}$ contemporaneidade, a mídia ocupa um dos lugares centrais na produção das discursividades, atuando tanto como meio de produção e circulação de textos e imagens, como fonte de discursos que fundamentam e orientam as relações sociais, podendo ser considerada com mais um poder que age sobre os corpos; afinal, ela é responsável pela visibilidade pública dos nossos corpos, ou seja, é através dela que os corpos estão cada vez mais visíveis. Os regimes de visibilidade funcionam como técnicas de gestão social. Se no século XIX, tais técnicas eram fortemente definidas pelo Estado, hoje, no século XXI, elas são também definidas pelo mercado, pois um corpo sujeito de mídia é um corpo mercadoria, um corpo exposto, um corpo com valor de 
troca. Segundo Orlandi (2012), o sujeito contemporâneo se individu(aliz)a na falha do Estado, produzindo-se assim, enquanto mercadoria.

Foucault (1987, p. 126) ao afirmar que "[...] em qualquer sociedade, o corpo está preso no interior de poderes muito apertados, que the impõem limitações, proibições ou obrigações", o autor já explicitava que micro poderes perpassariam todo o corpo social, acarretando em transformações e modificações de condutas nos sujeitos. 0 corpo social, ao longo dos séculos, se consolida como algo fabricado, influenciado por uma coação calculada, esquadrinhado em cada função corpórea, com fins de automatização. A noção de beleza exterior em relação aos corpos tornou-se tão importante na atualidade, que marca a nossa sociedade como sendo "a sociedade da aparência".

A noção de espetáculo, como desenvolvida por Debord (1997), permite-nos refletir sobre a natureza das representações corporais na contemporaneidade. Para o autor, "[...] toda a vida das sociedades nas quais reinam as modernas condições de produção se apresenta como uma imensa acumulação de espetáculos. Tudo o que era vivido diretamente, tornou-se uma representação" (DEBORD, 1997, p. 13). Segundo Debord, o espetáculo constitui o modelo de vida nas sociedades do capitalismo tardio contemporâneo, atuando por meio de diversas formas, especialmente através dos meios de comunicação.

Neste sentido, temos a espetacularização do corpo, do qual se tem ocupado a mídia. Nas sociedades contemporâneas, o corpo passa a ocupar o lugar central, e nas mídias se torna mais explicitamente um corpo que poderíamos chamar de corpo-espetáculo. Esta construção se articula fortemente com o consumo: é então, o surgimento do corpo-mercadoria. "O espetáculo é o momento em que a 
mercadoria ocupou totalmente a vida social" (DEBORD, 1997, p. 32).

As imagens passaram a ter um papel central na sociedade consumista, onde tudo se transforma em espetáculo, onde o mesmo "[...] não é um conjunto de imagens, mas uma relação social entre pessoas, mediatizada por imagens" (DEBORD, 1997, p. 14). A visibilidade midiática produz sujeitos que, além de tentarem se enquadrar nos estilos de vida sugeridos, também vigiam os outros sujeitos, tratando-os como inadequados através da interdição, como era feito com os sujeitos plus size.

O discurso midiático, com sua forte e invasiva onipresença na sociedade, constitui uma engrenagem poderosa como forma modeladora dos corpos. Porém, conforme afirma Ferreira (2008, p. 20), ao mesmo tempo em que esse discurso "[...] atua na direção da planificação niveladora de sentidos, [...] ele produz efeitos distintos, não controlados, e que acabam, por vezes, dada essa tensa alquimia em que somos jogados, a provocar o efeito inverso de diluição e esfacelamento dos sentidos" (grifo da autora). Considerando a heterogeneidade de discursos que a mídia possui, podemos concebê-la como uma prática discursiva, pois seus discursos além de veicularem informações, produzem cultura e geram ao espectador um sentimento de "pertencimento à determinada discursividade". Por isso, podemos afirmar que a heterogeneidade é constitutiva do discurso da mídia, pois nele "falam" diversos sujeitos.

Os estatutos adquiridos pelo corpo por meio de representações estéticas que são "marcadas" no corpo como sinais de uma cultura específica, são abordados segundo os significados que compreendem em seu universo cultural. Podemos analisar que a "ditadura" estética da moda é uma marca cultural do nosso tempo. A moda surge neste contexto como um universo de significações compartilhadas, 
que tomam o corpo como meio de expressão de subjetividade, de identificação, de comunicação entre os sujeitos e suas épocas.

A "fabricação do corpo" atualmente é tão forte quanto na Era Primitiva: a sociedade do século XXI infringe sobre o corpo a marca do seu momento sócio-histórico atual. Todas as tecnologias disponíveis no mais alto grau de conhecimento humano, como: cirurgias plásticas, implantes, farmacologia para emagrecer, aumentar, endurecer e estreitar formas - tudo para tornar o corpo ícone do momento: o belo e o ideal de acordo com sua cultura. No decorrer da história, a constituição dos corpos tem se alterado conforme os padrões e as mudanças socioculturais que ocorrem no interior de cada década. Nas sociedades primitivas, o corpo humano era instrumento de trabalho de subsistência, alheio ao sujeito e sua função era a de objeto do todo social. Na era greco-romana acreditava-se na extensão corpo/espírito, em que estes se complementavam na busca pela harmonia - "uma mente sã/um corpo são". E, assim, cada época foi transformando seus laços sociais e, junto deles, seus corpos.

A modernidade do século XIX, rompeu em relação à tradição e à corrida pelo progresso e pelo futuro, converteu o corpo em máquina operada pelo capitalismo em ascensão: ao contrário da era primitiva em que o trabalho, na forma de subsistência, era realizado para a manutenção das necessidades fisiológicas do corpo, na modernidade, o trabalho como forma de acumulação torna o corpo escravo da dinâmica do capital.

A busca por um "corpo perfeito" estará sempre sendo uma busca referida a um ideal inatingível, uma vez que as imagens veiculadas na mídia nada têm de humano e a promessa de felicidade absoluta, plenitude e atemporalidade 
aí contida, empurram as mulheres para a impossibilidade de adequar-se aos novos padrões estéticos.

Os corpos da publicidade e da fotografia colocam uma distância entre o real e o imaginário, afinal o que as fotografias propõem são corpos idealizados, abstratos, inatingíveis devido a todas as correções que estes corpos passam através das tecnologias para depois chegar até a grande mídia.

É possível afirmar que o corpo humano não parece ter se libertado das dolorosas amarras que ao longo dos tempos o confinaram, mas ao contrário, novas e mais poderosas forças socioculturais aparecem/aparecerão com o intuito de escravizá-lo cada vez mais. Como vimos, o fato de a moda e o capital nomearem os corpos como plus size, não quer dizer que os incluam de forma "completa" no mercado, pois eles ainda continuam sofrendo alterações para que ele seja possível no mercado de moda, para que ele seja desejado e consumível.

O que podemos concluir é que a condição não muda, mudam-se as nomeações para produzir um efeito de que esse corpo é possível, mas ele continua sendo impossível dentro dos aspectos de padronização. Porém, existem certas regras para ele ser considerado um corpo plus size, pois não é qualquer corpo gordo que a moda considera plus size, e isso é uma determinação de classe social. Portanto, as regras são falsas, pois o corpo não permanece o mesmo, ele é um corpo irreal.

Vivemos em uma sociedade na qual a busca por definições de regularizações no que diz respeito ao corpo transforma-se numa corrida rumo ao consumo. Tornou-se comum querer ter um corpo "da moda". Como vimos, à beleza tornou-se objeto de comércio a partir do século $X X$ e foi através disso que a mídia e a moda passaram a ditar os 
padrões de beleza, influenciando sempre na vida e nos corpos das mulheres.

Sabe-se que os efeitos de sentido do belo são progressivos e evoluem década após década. Cada momento influi no estereótipo de acordo com seus aspectos, sendo eles culturais, sociais, de classes, políticos ou religiosos. A mídia e a moda também possuem forte influência nos padrões de beleza impostos; fica no entanto marcado que a mídia tem um lugar privilegiado de constituição, formulação e circulação dos sentidos, pois ela, enquanto uma instituição, determina o que pode e o que não pode ser dito em seus diferentes espaços, em cada instância de circulação.

Foi possível compreender no decorrer desta pesquisa, que o nosso corpo, que até então acreditávamos ser nosso, individual, na verdade é invadido e modelado desde o início de nossas vidas pelas sociedades nas quais vivemos, e pelas forças que as regem, afinal, a construção das identidades dos sujeitos é feita através da "interação" entre o eu e os diversos âmbitos sociais, que mediam para o sujeito os valores, sentidos e símbolos.

As imagens do corpo nas narrativas midiáticas de moda carregam, portanto, uma ideologia, e estão associadas a um lugar de poder simbólico. Como defende Orlandi (2015, p. 9) "[...] não há neutralidade nem mesmo no uso mais aparentemente cotidiano dos signos. A entrada do simbólico é irremediável e permanente: estamos comprometidos com os sentidos e o político". Considerando também que os "[...] sentidos tem a ver com o que é dito ali, mas também em outros lugares, assim como o que não é dito, e como poderia ser dito e não foi" (ORLANDI, 2015, p. 32), a ausência dos corpos que não aparecem ali representados implica em um grande não dito acerca destes, indicando que não estão incluídos no lugar de destaque da moda na sociedade. 
Podemos concluir, com isso, que o processo de nomeação determina e é determinado pelas condições sócio-históricoideológicas de uma sociedade, neste caso, os sujeitos ao serem nomeados são assim determinados em sua condição de existência e em sua classe social, onde o corpo plus size não é considerado um corpo gordo, mas sim, um corpo de tamanhos maiores.

Por fim, podemos compreender que os estudos em relação ao corpo não se esgotam e que os deslocamentos no discurso midiático da moda, que passou a dar visibilidade aos corpos "diferentes" que até poucos anos não eram abordados, estão associados antes de tudo a estratégias mercadológicas. Assim, os corpos passam a ser nomeados, dando um efeito de inclusão/empoderamento, porém ainda existe uma forma de formatação sobre os mesmos, onde os padrões continuam sendo iguais, agora "contados" de outra maneira.

\section{NOTAS DE FIM DE TEXTO}

1 O conceito de dispositivo percorre o campo da filosofia (pós-estruturalista). Para autores como Foucault e Pêcheux, o dispositivo é uma noção estratégica na produção de seus pensamentos, com efeitos nos discursos, nas imagens e nos corpos. Ou seja, o dispositivo é o conjunto de ações que faz com que determinados corpos sofram de acordo com os discursos possíveis.

\section{REFERÊNCIAS}

CHALITA, Marco Antônio. A resposta da escola na preservação da obesidade no estado de Alagoas:

Estudo centrado em escolas do ensino médio da cidade de Maceió.2013. 386 p. Dissertação de Doutoramento apresentada à faculdade de Desporto da Universidade do Porto, Porto, 2013. 
CORBIN, Alain; COURTINE, Jean-Jacques; VIGARELLO, Georges. Prefácio. In: CORBIN, Alain; COURTINE, JeanJacques; VIGARELLO, Georges. História do corpo: Da Renascença às Luzes. Tradução de Lúcia M.E. Orth; revisão da tradução Ephraim Ferreira Alves. 5. ed. Petrópolis, RJ: Vozes, 2012. p. 7-13.

COURTINE, Jean-Jacques. Os stakhanovistas do narcisismo: body-building e puritanismo ostentatório na cultura americana do corpo. In: SANT'ANNA, Denise Bernuzzi De. (org.). Políticas do Corpo: elementos para uma história das práticas corporais. 2. Ed. São Paulo: Estação Liberdade, 2005. p. 81-114.

DEBORD, Guy. Comentários sobre a sociedade do espetáculo. In: DEBORD, Guy. A sociedade do espetáculo. Tradução de Abreu. Rio de Janeiro: Contraponto, 1997.

FERREIRA, Maria Cristina Leandro. A ciranda dos sentidos. In: ROMÃO, Lucília Maria Sousa; GASPAR, Nádea Regina. (orgs.). Discurso midiático: sentidos de memória e arquivo. São Carlos, SP: Pedro \& João Editores, 2008. p. 1322.

FOUCAULT, Michel. Vigiar e Punir: nascimento da prisão. Tradução de Raquel Ramalhete. Petrópolis: Vozes, 1987.

FOUCAULT, Michel. Microfísica do poder. 8 ed. Rio de Janeiro: Graal, 1989.

MILANEZ, Nilton. A disciplinaridade dos corpos: o sentido em revista. In: SARGENTINI, Vanice; BARBOSA, Pedro Navarro. Foucault e os domínios da linguagem: discurso, poder, subjetividade. São Carlos: Claraluz, 2004. p. 183-200.

MOTA, Jorge. Educação e saúde: contributo da Educação Física. Câmara Municipal de Oeiras, Lisboa, 1992.

ORLANDI, Eni. Discurso em Análise: Sujeito, Sentido e Ideologia. Eni Puccinelli Orlandi. $2^{a}$ ed. Campinas, SP: Pontes Editores, 2012.

ORLANDI, Eni. Análise de discurso: princípios e procedimentos. 12. ed. Campinas, SP: Pontes Editores, 2015.

RODRIGUES, Marlon Leal. Identidade: Movimento do Sujeito. In: PEREIRA, Danglei de Castro; RODRIGUES, Marlon Leal. Língua e Literatura I: questões teóricas e práticas. São Paulo: Nelpa, 2010.

SANT'ANNA, Denise Bernuzzi de. Transformações do corpo: controle de si e uso dos prazeres. In: RAGO, Margareth; 
ORLANDI, Luiz B. Lacerd; VEIGA-NETO, Alfredo. (orgs.).

Imagens de Foucault e Deleuze: ressonâncias

nietzschianas. 2 ed. Rio de Janeiro: DP\&A, 2005. p. 99-110.

SCALZO, Marília. Jornalismo de Revista. São Paulo:

Contexto, 2003. (Coleção Comunicação).

SILVA, Lucimar Aparecida. Representações do corpo

feminino na moda Plus size no Brasil: um olhar multimodal em capas de revistas na versão online. 2015. 152p. Dissertação (Mestrado) Universidade Federal de Viçosa, Viçosa, MG, 2015.

SOUZA, Bárbara Pavei. O corpo feminino plus size: nomeação e/ou condição? 2017. 116p. Dissertação (Mestrado em Ciências da Linguagem). Universidade do Sul de Santa Catarina, Palhoça, SC, 2017.

WOODWARD, Kathryn. Identidade e diferença: uma introdução teórica e conceitual. In: SILVA, Tomas Tadeu da (org.). Identidade e diferença: a perspectiva dos Estudos Culturais. Petrópolis, RJ: Vozes, 2012. p. 6-68. 